\title{
Da chibata ao magistério: a trajetória da educação feminina no Brasil patriarcal
}

\author{
A formação da leitura no Brasil. \\ LAJ OLO, Ma risa; ZLBERMAN, Regina.
}

São Paulo: Ática, 2001. 374 p.

Embora o livro $A$ formação da leitura no Brasil, escrito pelas professoras doutoras Marisa Lajolo e Regina Zlberman, tenha sido public ado em 2001, a recente leitura a tenta de um dos seus capítulos motivou-me a demonstrar a sua atualidade. O capítulo "A leitora no banco dos réus" pode ser retomado em tempo para discutimos o papel da literatura como meio à educação feminina, pois traz à baila discussões sobre as condições de leitura e educação no Brasil colonial sob o qual uma literatura inexperiente se edificava. As autoras relatam diversas visões sobre a mulher brasileira, desde opiniões de viajantes estrang eiros a o pensa mento nacional, sem deixar de apontar as conseqüências desses olhares para a formação intelectual da mulher

0 início das atividades intelectua is da mulher, dizem as autoras, coincide com o nascimento da modernidade. Em um breve contexto histórico, recordamos que à época o advento do protestantismo trouxe severas preocupações à igreja. A necessidade de angariarnovos a liados para a contra-reforma fez com que a burguesia ascendente fosse 0 alvo, vista como único caminho: "o negócio era bom para os dois lados: a burguesia fomece à igreja clientela segura, que, da sua parte, recebe instrução a investir no futuro" (p. 237). A partir desse momento, discussões sobre a educação da mulhervêm à tona: "é misterpreparara mulher para assumir as funções domésticas de que a nova camada emergente carece, destacandose entre estasa educação das crianças" (p. 237). O sentimento da matemidade e da intimidade surge como altema tiva à rigideze distancia mento que a mãe, senhora da casa-grande, tinha do filho pequeno. A criança criada pela negra experiente tinha hábitos que se misturavam aos dos moleques da roça, e pela nova ordem familiar burguesa o filho deveria ser criado no regaço da mãe, sob a proteção de seu lar, livre de influências, principalmente dos escravos.

A instituição de um novo papel para a mulher fez dela um instrumento assaz importante na ascendência política e econômica de sua família. Ao saírem da casa-grande e se instala rem nos sobrados, as famílias de origem nobre efetuaram uma mudança que iria além do espaço físico. A cidade, tida como lar de desordeirose vagabundos, precisou se adaptar aos novos moradores. Ruas infestadas e fedorentas foram limpas, novas tendências trazidas pela corte portuguesa eram dissemina das e aceitas, a europeização foi instaurada, elevar - Brasil a o sta tus de pa ís c iviliza do foi pré-requisito para o reconhecimento de sua independência. A incumbência feminina de cuidarda casa, dos filhos e da aparência física e social do marido era tarefa árdua. A mulher precisou se transformar, antes pesada, feia e de gestos rudes, ${ }^{1}$ ela teria de ter então o aspecto doentio idealizado pelo romantismo, cuja leveza e delicadeza dos atos eram impresc indíveis. As relações se estreitavam à medida que o espaço entre uma edificação $e$ outra aumentava. O burguês vivia só, via o seu lar como recanto, primava por sua intimidade, desde que o isolamento não fosse completo. Festas, bailes, jantares e saraus eram oferecidos à alta sociedade. Criou-se a necessidade dos bons modos, e à mulher eram dadas as possibilidades de educação, como o aprendiza do de litera tura e música. A elegância do vestido deveria combinar com o francês e o piano, que tomavam a senhora uma verdadeira madame. Na França do século XVIII, o assunto já tinha resultado no dilema: e se o 'esboço intelectual' feminino se transformasse em traços seguros, com mulheres intelectualizadas para apoiar com braços e idéias a revolução e, ao mesmo tempo, tomar o choque entre os sexos iminente? Era o poder que estava em jogo.

No Brasil, com uma realidade ideologicamente 'um pouco' diferente, a educação das mulheres foi admitida não exa tamente pelo apelo de Nísia Floresta, mas pelo anúncio de que elas poderiam ajudar na conc retização do plano político pensa do para o país. Podemos, aliás, imaginar que essa "educação para todos" estaria fomentada sob o mesmo intuito do "liberdade para todos". Nos do is 
lemas encontramos o mesmo aspecto: "todos" não eram a maioria, "educação" e "liberdade" seriam vigiadas, mulheres e negros estariam à deriva doscaprichos do Estado. Educa-se porque é conveniente, liberta-se para gerarma is luc ros.

Diante dessa nova necessidade, as responsa bilida des a tribuída à mulherirão formar um novo tipo de leitora à qual a literatura precisaria se adaptar: "os textos passam por mudanças estrutura is, a pa recem novos gêneros literários, ma is prosa ic os, e começa a desgastarse o emprego de expressões eleva das" (p. 237). ${ }^{2}$ De fato, o aumento de obras em prosa fez com que um número crescente de leitoras fosse abarcado. No entanto, essa relação de causaefeito está muito mais ligada ao déficit de oportunidades do que arraigada na potência intelectual de cada sexo.

Dentre a imensidão de novos gêneros, aquele de tendência épica, "que priorizava os enred os romanescos dissocia dos da religiã o" ( $p$. 237), ganhava cada vez mais destaque, sobretudo os textos que "valorizavam a personagem feminina enquanto protagonista de grandes amores" (p. 237). O fato de romances possuírem a religião tanto ma is distante não quer dizerque era m a vessos a ela: a lguns mais, outros menos, encarregavam-se de transmitir valores religiosos com um novo rótulo, valores natura is, que toda mulhernecessitava terporconsciência própria. A preferência feminina por obras romanescas condizia, de certa forma, com o sentimentalismo burguês que ao mesmo tempo repreendia o gosto. A mulher-mãe assume crescente sta tus de santific a ção pelos sofrimentos e dificuldades que enfrentava na literatura brasileira da segunda metade do século XIX

No entanto, como o conteúdo dos romances não era perfeitamente previsível, diziam à época que poderiam suscita rmudanças no comportamento feminino, desencadeando "rebeldia", questionamentos e "falta de juízo", opinião própria. 0 que mais impressionou foi a alta tolerância das mulheres em relação à histórias comoventes. Muitas acredita vam na possibilidade de transformarem-se nas protag onistas dos livros que liam freqüentemente. As solteira s sonha va m com uma união a rreba ta da pela paixão e felicidade, enquanto algumas já casadas pensavam a penas na possibilidade de pedir ao marido quantos livros coubessem no entrelugar do tédio que as separava de si mesmas. Não importando exatamente a causa o cresc imento a celerado da indústria gráfica era assustador. Além dos romances, os folhetins, as revistas, tod os os meios de comunic ação, exibiam um pequeno texto que fosse para garantir o público feminino. A venda era certa. Entre destacar-se como indivíduo ou "dissolver-se na massa", ${ }^{3}$ a mulher levaria algumas décadas desde o estopim de sua aculturação para compreendera importância do primeiro.

Os primeiros indícios sobre as controversas conseqüências dasnovas leitoras foram glosa das por Molière, França, na segunda metade do século XVIII. Pelo teatro, o crític o divertia-se com a possibilidade de apresentar ao público os "p erigos resultantes da nova situação". Para Molière, a a meaça era visível: em pouco tempo as "sabichonas" governariam, além de suas casas, seus próprios maridos. E mais, logo as conseqüências observadas dentro do lar seriam alçadas a os outros aspectos da vida social: os "pendores intelectuais" femininos, adverte Molière, poderiam dominar a literatura por meio da exigência que faziam a os autores. Não muito depois, dizem Marisa Lajolo e Regina Zlberman, o gosto feminino pela leitura seria tachado de vadiagem.

No Brasil, o ócio feminino foi combatido com - auxílio da medicina e dos meios de comunic ação (estes últimos a grada vam a o homem por respeito e à mulher, como vimos acima, pornecessidade). Os médic os a lertavam sobre os riscos do passatempo, e a moral reclamava o tempo perdido que poderia ser a proveitado para segurar moças namoradeiras em casa ou empregado em outras ta refas do lar. O fato é que sempre havia algo mais útil para fazer. Contudo, o gosto pela leitura foi responsável porintroduzira mulherno mundo das letras, sendo o hábito decisivo para a sua educação, e sem o deixar de ser para o processo de instrumenta lização do sexo. Agora a lfa betizada, a mãe era responsável pela educação regular do filho, ensinando-o, a lém dos bons costumes, aquilo que o levaria à Faculdade de Medicina. Seduzido pelo segundo objetivo, o Estado reconheceu o esforço, e nesse momento a literatura nacional perde parte do estigma.

Na segunda metade do capítulo, as autoras abordam o interesse da colônia, recém-desligada da metrópole, em constituiruma nova nação com traços objetivos da europeização. A educação tida como meta chegava à mulher sob o intuito de melhorar a educação dos filhos, homens, obviamente. Descritascomo ignorantes e frívolas, mais violentas que seus maridos, as mulheres brasileiras do século XVIII desenvolvia m atividades essencialmente colonia is e domésticas, como dar ordens a os negros, reger as a tividades da casa, zelar pelo bem-estar da família. Sua 
intelectualidade não era sequer mencionada pelos viajantes estrangeiros que deixavam suas impressões sobre os costumes do país. Para um deles, Henry Koster, o fato ma is assombroso era vê-las menos "humanas que os homens". A justific a tiva era dada pelo "esta do de ignorância em que o sexo vivia", como se somente ao homem uma "desumanização" fosse permitida, sendo ele à época tão ignorante quanto a "fêmea". Da chibata a o magistério, a mulher brasileira do século XVIII passa a o século XX em uma escala ascendente de conquistas, o que não a livraria de características como instrumento para a consolidação de polític as socia is.

Como requisito à modernização, a educação de base deveria ser fomecida pelo Estado, e porque não de forma mais agradável? Menos homens humilhados, ma is mulheres no magistério. A escola seria consolidada como segundo lar, e a professora, caracterizada pelo 'instinto' ma temal, seria tão doce e severa tal qua na educação de seus próprios filhos. 0 século XIX tomou-se decisivo para a manutenção da cultura patriarcalista no Brasil, que então poderíamos chamar de "descentraliza do", devendo a mulher prestar contas não só ao marido, mas também a toda a sociedade e, se isso nã o basta sse, a o Esta do. Rea fimamos, junto a Lajolo e Zlberman, que a educação feminina foi fomentada sob pena de atrasar o progresso da nação. A participação da mulher no plano social deveria ser treinada e exercitada, ainda que necessitasse de 'apoio', vigilância, a o longo dasdécadas.

O papel dos romancistas brasileiros para a "autopromoção" da literatura impulsionava as vendas de exemplares recheados de histórias cujas personagens femininas, instruídas e refinadas, serviam para esclarecer a dicotomia entre a ficção e realidade. Do mesmo jeito, romancesindianistas traçavam a figura nacional, valendo-se de parâmetros da cultura européia. A "voz dissonante" de Machado de Assis destacava-se ante o coro unilateral, tendo o autor passeado pelos extremos do pensamento nacional e construído suas persona gens sob um conjunto de valores controversos à época. De todo modo, a participação dos romancistas fo crucial para que se desenvolvesse um processo de emancipação feminina, tal qual demonstravam ser as personagens impressas.

Quem também teve um papel importante na ascensão da literatura dita feminina foi a figura do ledor, posição ocupada pelo jovenzinho da casa. Segundo as autoras, ele era um ícone da ma nifestação do gosto literário da s mulheres, que faziam da hora da leitura um culto, la rgavam seus afazeres domésticos e, absortas nas palavras entoadas pelo menino alfabetizado, deixavamse levar por histórias a rrebatadoras, de onde a moral patria rc al ja ma is sa iu das entrelinhas.

Durante essa trajetória, as professoras Marisa Lajolo e Regina Zlberman narram parte da história da mulher brasileira em um período marcado por sua inclusão social sob o signo da instrumentalização do sexo. Pouco a pouco, concessões foram feitas às mulheres e transforma das em contingência. Da casa-grande para o sobrado, deste para a escola, em cada lugar a mulher desempenha uma função de retorno garantido ao patriarca e ao Estado. Aquele entrelugar ainda ressoava: quanto do homem restava entre a mulher e ela mesma? As dúvidas continua va m ontológic ase devida mente maquiadas para que, enquanto a mulherbuscar respondê-las, permaneça instrumento para o bem da nação.

\section{Notas}

${ }^{1} \mathrm{~A}$ retomada da descrição feita por Gilberto Freyre em Sobrados e mocambos (FREYRE, 2000) serviu de contraponto às novas exigências ao sexo feminino.

2 Parte dessas modificações são causadas pelo que Gilberto Freyre admite no capítulo IV do livro Sobradose mocambos, quando diz que há na mulher um senso objetivo, téc nico, enquanto o homem é descrito como um ser de acepção subjetiva, cuja abstração é mais fácil (FREYRE, 2000).

${ }^{3}$ A expressão é utiliza da por Gilberto Freyre a o comparar os papéis socia is dos sexos.

\section{Referência bibliográfica}

FREYRE, G. Sobrados e mocambos. 12. ed. Rio de J a neiro: Record, 2000.

Daiana da Rosa Acordi

Universidade Federal de Santa Catarina 